Document downloaded from:

http://hdl.handle.net/10251/145194

This paper must be cited as:

Cerrillo, JL.; Palomares Gimeno, AE.; Rey Garcia, F.; Valencia Valencia, S.; Pérez-Gago, MB.; Villamón-Pérez, D.; Palou-Valls, L. (02-0). Functional Ag-Exchanged Zeolites as Biocide Agents. ChemistrySelect. 3(17):4676-4682. https://doi.org/10.1002/slct.201800432

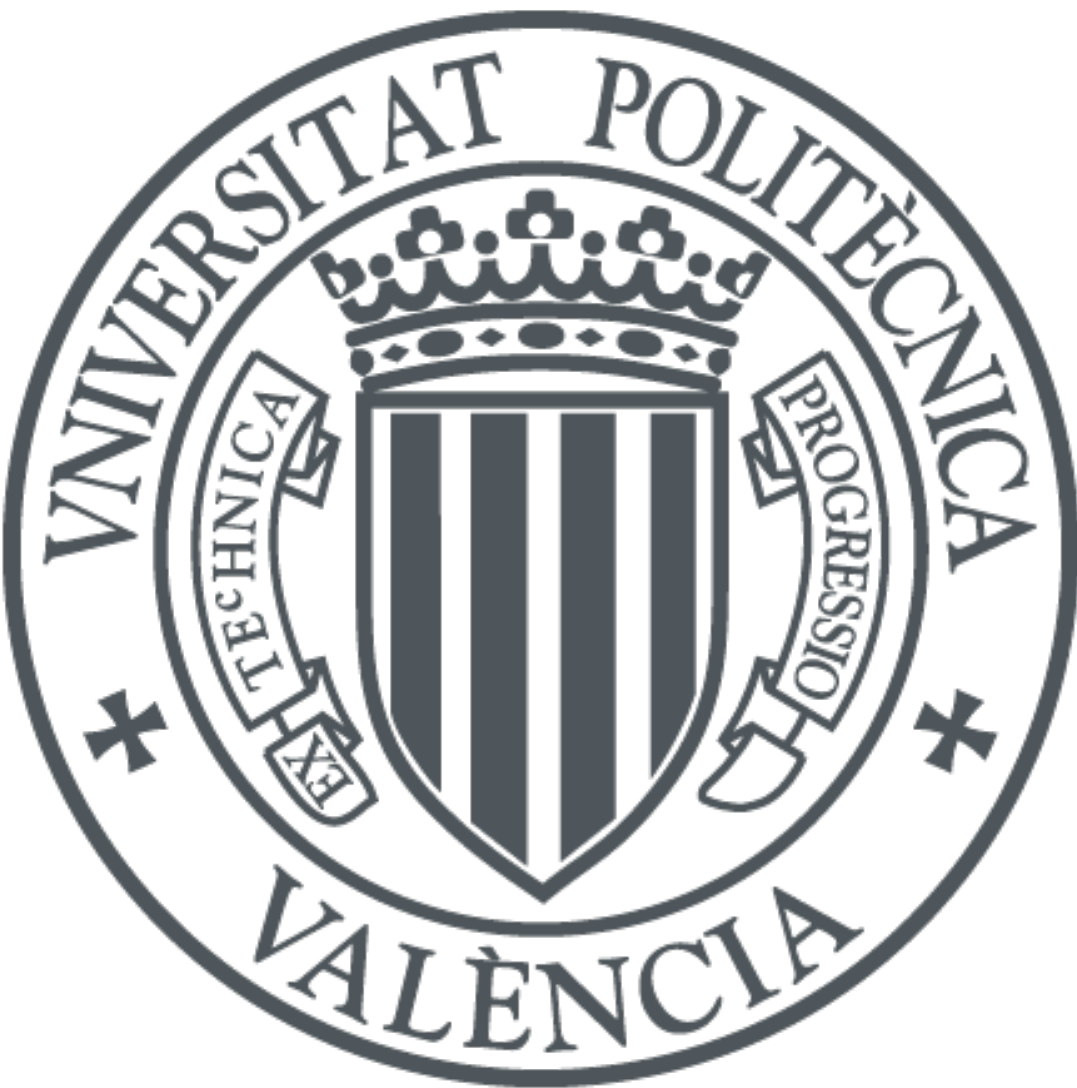

The final publication is available at

https://doi.org/10.1002/slct.201800432

Copyright John Wiley \& Sons

Additional Information

"This is the peer reviewed version of the following article: Cerrillo, José Luis, Antonio Eduardo Palomares, Fernando Rey, Susana Valencia, María Bernardita Pérez-Gago, Diana Villamón, and Lluís Palou. 2018. Functional Ag-Exchanged Zeolites as Biocide Agents. ChemistrySelect 3 (17). Wiley: 4676 82. doi:10.1002/slct.201800432, which has been published in final form at https://doi.org/10.1002/slct.201800432. This article may be used for non-commercial purposes in accordance with Wiley Terms and Conditions for SelfArchiving." 
DOI: $10.1002 /$ slct.201800432

Full Paper

Materials Science inc. Nanomaterials \& Polymers

Received: 13.^February.^2018

Accepted: $13 .^{\wedge}$ April.^²018

\section{Functional Ag-Exchanged Zeolites as Biocide Agents}

José $^{\wedge \wedge}$ Luis Cerrillo, ${ }^{[a]}$ Prof. Antonio ${ }^{\wedge \wedge}$ Eduardo Palomares, ${ }^{*}\left[\right.$ a] Prof. Fernando Rey, ${ }^{[a]}$ Dr.

Susana Valencia, ${ }^{[a]}$ Dr. María^^Bernardita Pérez-Gago, ${ }^{[b]}$ Diana Villamón, ${ }^{[b]}$ Prof. Lluís

Palou $^{[b]}$

[a] <orgDiv/>Instituto de Tecnología Química, <orgName/>Universitat Politècnica de València - Consejo Superior Investigaciones Científicas, <street/>Avenida de los Naranjos s/n, <postCode/>46022 Valencia, <country/>Spain

E-Mail: apalomar@iqn.upv.es

[b] <orgDiv/>Centro de Tecnología Poscosecha (CTP), <orgName/>Instituto Valenciano de Investigaciones Agrarias (IVIA), <street/>Ctra. CV-315^^ km 10.7, <postCode/>46113 Moncada, <country/>Spain

<pict> Supporting information for this article is available on the WWW under <url>http://dx.doi.org/10.1002/slct.201800432</url>

bactericides

biocidal materials

fungicides

silver

zeolites

The battle against microorganisms using non-toxic materials is a necessity nowadays. In this work, the bactericide and fungicide properties of diverse silver-zeolites are investigated, and they are related to their physical-chemical properties. 
Materials based on silver are used for controlling different pathogenic microorganisms. However, the influence of the silver carrier in the biocidal activity of the material has been scarcely reported. The present research is focused on studying the influence of zeolite properties on the biocidal activity of silver-exchanged zeolites, acting as reservoirs of silver species. The biocidal action of Ag-Faujasite (Ag-FAU) and Ag-Linde Type A (Ag-LTA) zeolites, containing different silver contents, is studied against different types of bacteria and fungi. Importantly, zeolite structure is found to be a significant parameter for controlling the antibacterial activity of Ag-exchanged zeolites. The results show that Ag-FAU presents a higher activity than Ag-LTA, because the topology of FAU combined with its highest Si/Al ratio favors the formation and release of silver species with important biocidal activity. Some insights on the bactericidal mechanism of Ag-zeolites are envisaged by means of high resolution transmission electron microscopy, showing the multi-targeted biocidal action of $\mathrm{Ag}$ species released from zeolites. Besides, it is shown that Ag-zeolites are more active against bacteria than fungi. Antifungal activity is highly dependent on the fungi species and the structure of the zeolite is not as determinant as it is for the antibacterial activity.

\section{Introduction}

Diverse types of microbes as bacteria, virus, yeast and fungi are present in daily lives. They populate food, tap water, air, furniture and all kind of surfaces. These microorganisms can develop dangerous health problems to human beings. ${ }^{[1]}$ Actually, only in the United States, it is estimated that healthcare associated infections produced by these microbes occur in about two million patients per year with a total number of deaths of 99,000 and a cost of $\$ 33$ billion each year to the public health system. ${ }^{[2]}$ A second issue is the increase of the microorganism resistance against traditional antibiotics. Then, the development of new pharma-treatments has attracted the attention of researchers for microbial infection control. Also, there is a very active research focused on finding new types of biocide materials that could prevent the development of pathogens. These new bioactive materials must be successfully incorporated as components of active packaging, textiles, health and home products or even they can be directly integrated into edible coatings for fruits and vegetables. 
Consequently, these biocide materials must satisfy other requirements such as environmental safety, low toxicity, easy fabrication and cost-effectiveness. ${ }^{[3]}$

Silver is a natural biocide element against bacteria, fungi, protozoa, yeast and certain viruses known since ancient times. ${ }^{[4]}$ Nowadays silver is still used as silver-imbedded equipment in hospitals including surgical tools, catheters, needles, dental filling materials, bandages medical dressings and healthcare furniture. ${ }^{[5-8]}$ Even at low concentrations, silver is one of the strongest biocide agents against a huge range of microorganisms. Furthermore, silver species are considered as very low toxic for humans. ${ }^{[9]}$ Therefore, silver seems to be a possible solution to design new biocide materials. However, it is advisable to control the release of silver into the media for reducing costs and environmental concerns without losing treatment effectiveness. ${ }^{[10]}$ Silver containing ceramics have been proposed for packaging, disinfection of medical supplies and decontamination of surfaces. ${ }^{[11]}$ The main drawback of ceramics is the very low surface area, resulting in a low contact of the biocide material with the surrounding media. Then, high surface area materials with controlled silver release properties could be advantageous alternatives to ceramics. On this regard, zeolites are promising inorganic materials for silver release.

Zeolites are structured microporous silicoaluminates with cation exchange properties widely used in industrial processes. ${ }^{[12--17]}$ The ion-exchange properties of zeolites permit their use as inorganic reservoirs for silver ions. In addition, the flavourless, odourless and harmless properties of zeolites and the large number of zeolitic topologies make them attractive candidates as supports of silver for biocidal applications. Demirci et ${ }^{\wedge}$ al. have evaluated the biocide effects of silver-exchanged commercial zeolites (Linde Type A and Faujasite X) against some bacteria (Escherichia coli, Staphylococcus aureus, Pseudomonas aeruginosa and Bacillus cereus), yeast (Candida albicans and Candida glabrata) and fungi (Aspergillus niger and Penicillium vinaceum). ${ }^{[18]}$ In addition, the influence of the silver content on the bactericidal effect of some zeolites has been studied, ${ }^{[7--11,19--21]}$ and even there is a commercial silver-zeolite named as Zeomic ${ }^{\circledR} .^{[11,22]}$ However, the fungicidal efficacy of silver-zeolites has been scarcely studied compared to their bactericidal effect, so far to the best of our knowledge, only the fungicidal effect of the silver-exchanged Zeolite A, Faujasite X and 
Mordenite has been studied. ${ }^{[18,23-24]}$ More recently, we have reported the control of the most economically important citrus postharvest disease, citrus green mold caused by Penicillium digitatum, using a series of Linde Type A zeolites (LTA) and Faujasite zeolites (FAU) with different silver contents. ${ }^{[25]}$

In this work, we evaluate the antibacterial and antifungal properties of different silverexchanged LTA and FAU zeolites in in ` $^{\wedge}$ vitro experiments. These zeolites have been selected because they can be prepared within a very broad range of aluminium content, with different silver loadings and they possess different structures. The zeolites have been ion exchanged with $\mathrm{Ag}^{\mathrm{I}}$ in order to obtain zeolites with high and low silver content. The silver containing materials have been characterized by different techniques and their physicochemical properties have been correlated to their biocidal activity.

\section{Characterization results}

The Ag-zeolites have been prepared, as it is described in SI (preparation of samples), by a conventional ion exchange procedure using several solutions with different $\mathrm{AgNO}_{3}$ concentration in order to prepare catalysts with different silver content. The elemental composition of all the samples, measured by inductively coupled plasma optical emission spectroscopy (ICP-OES), is shown in Table ${ }^{\wedge} \wedge 1<\operatorname{tabr} 1>$. As it can be seen, the parent $\mathrm{Na}<$ ?_>LTA zeolite has a $\mathrm{Si} / \mathrm{Al}$ ratio of 1 , this is a chemical composition of $\mathrm{Na} 0.5\left(\mathrm{Al}_{0.5} \mathrm{Si}_{0.5} \mathrm{O}_{2}\right) \cdot \mathrm{xH}_{2} \mathrm{O}$, while the parent $\mathrm{Na}<$ ?__FAU zeolite has a $\mathrm{Si} / \mathrm{Al}$ ratio of 2.4 , with a chemical composition of $\mathrm{Na}_{0.3}\left(\mathrm{Al}_{0.33} \mathrm{Si}_{0.7} \mathrm{O}_{2}\right) \cdot \mathrm{xH}_{2} \mathrm{O}$.

The Ag-exchanged zeolites present the same $\mathrm{Si} / \mathrm{Al}$ ratios than parent zeolites, confirming that the cationic exchange process does not produce any dealuminization of the zeolites. Some zeolites were prepared with a low silver content $\left(1-2^{\wedge \wedge} \mathrm{wt} . \% \mathrm{Ag}\right)$, close to that used in biocide commercial products containing silver, ${ }^{[22]}$ and others were prepared with a high silver content, close to a complete $\mathrm{Ag}^{\mathrm{I}}$ ion exchange. The exchange degree has been calculated as the $\mathrm{Ag} / \mathrm{Al}$ molar ratio, expressed as percentage, since aluminium in the zeolite framework generates a negative charge that is compensated by a cation, in this case $\operatorname{Ag}^{\mathrm{I}}$, which substitutes $\mathrm{Na}^{\mathrm{I}}$ present in the parent zeolites. 
The Ag-containing zeolites and the parent zeolites have been characterized by X-ray diffraction $(\mathrm{XRD})$. Figure $^{\wedge} \wedge 1<$ figr $1>$ shows the corresponding XRD patterns. It can be seen that there are no extra-phases different to LTA and FAU zeolites in the exchanged materials, as it is deduced from the absence of any XRD peak that cannot be observed in the original zeolites. Also, none of the samples show any visible amorphous material or any peak associated to metallic silver or silver oxide, showing that the silver ion exchange process does not modify the structure of the zeolite. These results indicate a good metal distribution on the zeolitic matrix. ${ }^{[20,26]}$ On the other hand, the differences in the intensities of the XRD peaks are due to the very different scattering factor of silver cations compared to the sodium cations of the original zeolites.

A quantitative energy-dispersive X-ray spectroscopy (EDS) study carried out in different areas of the zeolites shows similar $\mathrm{Si} / \mathrm{Al}$ and $\mathrm{Ag} / \mathrm{Al}$ ratios than those obtained by ICP-OES. The coincidence of the results obtained with a punctual technique (EDS) with those obtained with a bulk technique (ICP-OES) indicates a homogenous distribution of silver in the diverse zeolites. This is supported by the elemental mapping of the samples, carried out by the combination of EDS and FESEM techniques, obtaining a detailed distribution of the atomic content. ${ }^{[27]}$ Figure $^{\wedge \wedge} \mathbf{2}<$ figr $2>$ shows as blue points the silver atoms present in the silver exchanged LTA zeolites. In both cases a homogenous distribution of silver in the zeolite crystallites was observed. Analogous results were obtained for FAU zeolites exchanged with silver. Moreover, the FESEM images before and after the silver exchange showed no significant differences among the parent zeolites and the Ag-exchanged materials in terms of morphology, remaining the typical morphology of LTA zeolites with cubic particles, ${ }^{[26]}$ as it can be observed in Figure $\wedge^{\wedge} 2<x$ figr2>. The same results (not shown) have been observed for FAU zeolites but with octahedral morphology. ${ }^{[20,26,28]}$

\section{Biocidal results}

\subsection{Bactericidal outcomes}

The bactericidal activity against E. coli and S. aureus of the different Ag-zeolites was determined as the minimal inhibitory concentration (MIC); that is, the lowest concentration of 
zeolite incorporated into the nutrient broth that inhibits the bacterial growth; in this way, the lowest MIC means the highest biocide activity. Figure ${ }^{\wedge} \wedge 3<$ figr $3>$ shows the results obtained with the LTA zeolites. The results proved that while the parent zeolite (LTA-1<?_>Na) did not exhibit any bactericidal effect, this was very important for the zeolites containing silver. As it can be observed, the lowest MIC value and consequently the highest bactericidal activity were obtained with the zeolite containing the highest silver content. The relationship between the increase in silver content and the MIC reduction, and the absence of biocidal activity of the Na-zeolite demonstrates that silver is the actual bactericidal agent when it is exchanged in zeolites. The results observed in Figure^^3<xfigr3> also show that the LTA-1<?_>Ag zeolites are more active against $E$. coli than against $S$. aureus, i.^e. there is a better activity against Gram-negative bacteria than against Gram-positive bacteria.

The different antimicrobial activity has been related to the different cellular wall of these bacteria. ${ }^{[6,20]}$ Gram-positive bacteria have only one thick peptidoglycan layer in the cellular wall, whilst Gram-negative bacteria have a very thin peptidoglycan layer that is accompanied by a second cytoplasmic layer. The better biocidal results obtained against Gram-negative bacteria using Ag-exchanged zeolites can be related to the lower thickness of the peptidoglycan layer in these bacteria. Therefore, it seems that the second cytoplasmatic layer of Gram-negative bacteria does not prevent the biocidal activity of silver. Then, thicker peptidoglycan layer results in lower bactericidal activity of the silver zeolite.

In order to study the influence of the zeolite topology on the biocidal activity, the bactericidal properties of a LTA-1 zeolite containing a low content of silver were compared with those of a FAU-2.4 zeolite with a similar silver content (Figure ${ }^{\wedge} \mathbf{4}<$ figr4>). The results revealed significant differences between the two zeolites, being the FAU-2.4 sample the most active one. The observed biocidal activities can be related to the different structures and/or $\mathrm{Si} / \mathrm{Al}$ ratios of the zeolites. These properties control the silver speciation and the easiness of releasing silver to the media, regulating the antibacterial activity of the materials. Regarding the topology, since the FAU zeolite presents a Faujasite structure with large pores and cages, it is considered a more accessible structure than the LTA structure. This makes easier the silver liberation to the media, improving the bactericidal properties of the FAU zeolite. 
Regarding the Ag speciation, different silver species have been described in diverse zeolites; i) well-dispersed silver oxides on the surface of the zeolite; ii) isolated and non-isolated monovalent silver cations $\left(\mathrm{Ag}^{\mathrm{I}}\right)$ placed in non-framework positions as compensating cations; and iii) cationic silver clusters. ${ }^{[29--32]}$ The zeolite with the highest biocidal effect is the sample FAU-2.4, which possesses a Si/Al ratio of 2.4. The higher Si/Al ratio of FAU-2.4 compared to LTA-1 sample, together with the presence of extralarge cavities in its structure, could stabilise the silver as isolated species, since averaged distance between $\mathrm{Ag}^{\mathrm{I}}$ cations could be much larger in the FAU sample than in the LTA, resulting in a lower tendency to form silver clusters in the former one. This isolated $\mathrm{Ag}^{\mathrm{I}}$ ions seem to be more easily released to the media and, therefore, they can interact more easily with the bacterial cell.

Likewise, Figure ${ }^{\wedge} 4<x$ xigr $4>$ shows that the antibacterial action of FAU-2.4<?_>Ag is higher against Gram-negative bacteria (E. coli) than against Gram-positive bacteria $(S$. aureus), similarly to the observed biocidal activity of LTA zeolites, as discussed above. It is supposed that the bactericidal mechanism of Ag-zeolites is similar to the multi-target biocidal mechanism of silver, which has been related to the large affinity of silver for linking to the Sgroups present in different bacterial organelles resulting in an alteration of the organelle functions. In addition, silver can interact with the membranes making impossible the ion exchange processes necessary for the surviving of the cells. ${ }^{[33]}$ In order to analyse the performance of Ag-zeolites against $S$. aureus, two biocidal tests were made, one containing Ag-zeolite and the other one without zeolite that was used as a control sample. The prepared suspensions were studied by HRTEM after incubation. Figure ${ }^{\wedge} \wedge 5<$ figr5> (left) shows the control sample where the intern organelles and the extern membrane of the bacteria are perfectly preserved. However, the image (Figure ${ }^{\wedge} 5<x$ figr $5>$ right $)$ of the sample containing the silver material exhibits several crystals of the Ag-zeolite but also a cell with a plain electronic density, which indicates the destruction of the bacterial membrane and the organelles, resulting in the death of the bacteria.

The Ag distribution across the Ag-zeolite-bacteria system was studied by using the mapping technique $(\mathrm{EDS})$. Figure $^{\wedge \wedge} \mathbf{6}<$ figr6> shows the different element distribution in the system. The Si distribution clearly indicates the presence of zeolite crystals in the media and 
its stability. On the other hand, Os distribution indicates the areas in which bacteria are present $\left(\mathrm{OsO}_{4}\right.$ used as selectively dye for organic material). Besides, it can be seen that $\mathrm{Ag}$ is distributed along the bacterial cells. This clearly indicates that selective Ag migration from zeolite to cell is involved in the bactericidal activity. Therefore, we can figure up the process that leads to bactericidal activity starting from the release of silver cations from the zeolites into the media; then silver released species are selectively trapped by the bacteria, causing its death. The presence of silver species on the membranes and inside the bacterial cells demonstrates that the silver species formed on the zeolite and discharged to the media are the biocidal agent and that a multiple attack against vital points of the bacteria is produced.

\subsection{Fungicide outcomes}

The in ${ }^{\wedge}$ vitro antifungal activity of Ag-exchanged zeolites (FAU-2.4<?_>Ag and LTA-1<?_>Ag) against eight different fungi (Monilinia fructicola (MC), Alternaria alternata (AA), Geotrichum citri-aurantii (GC), Penicillium digitatum (PD), Penicillium italicum (PI), Penicillium expansum (PE), Botrytis cinerea (BC) and Rhizopus stolonifer (RS)) was studied. These fungi were selected because they are responsible for very important economic losses through the supply chain of fresh fruits from harvest to market.

The antifungal activity of some Ag-exchanged zeolites with different silver content (low and high) was compared with the biocidal activity of FAU and LTA zeolites in their sodic form (without silver). It was observed that zeolites without silver showed a negligible fungicidal activity even at high concentrations (data not shown). On the other hand, the same zeolites containing silver have important antifungal properties. Figure ${ }^{\wedge \wedge} \mathbf{7}<$ figr $7>$ a shows the results obtained when a specific amount of $\mathrm{Ag}-\mathrm{FAU}<?+>2.4$ with a high silver content were introduced in the fungal growth medium to obtain a $0.5 \%$ of Ag-zeolite in the growth medium. For each fungal species, the percentages of inhibition are reported for the period of time (days) after which the mycelial growth in control plates (PDA without Ag-zeolite) completely covered the entire plate. It was observed an important antifungal activity for this zeolite, resulting in more than $80 \%$ of inhibition of the growth of all the studied fungi with the exception of G. citri-aurantii (GC). The results obtained with the FAU zeolite containing a 
lower silver content are also shown in the same graph (Figure ${ }^{\wedge \wedge} 7<x$ figr $7>$ b). It can be observed, likewise, that this zeolite has an important antifungal activity against all the fungi except GC. This can be explained because the different reproductive system of this fungus. The rest of tested fungi are filamentous molds that form mycelium, hyphae and conidia (asexual spores formed in special reproductive organs), whilst G. citri-aurantii is considered as a yeast-like fungus. This is because its reproductive cells or spores are produced by a process of disarticulation of the hyphae. ${ }^{[34]}$ According to the results, it seems that this distinctive reproductive system plays a key role on the resistance of this fungal species to the biocidal action of the Ag-zeolites.

Since the results of these experiments were satisfactory with respect to the fungal growth inhibition, the concentration of the Ag-exchanged FAU zeolite with low silver content was lowered in the growth medium from $0.5 \%$ to $0.05 \%$. As it can be observed in Figure $^{\wedge \wedge} \mathbf{7}<x$ figr $7>\mathbf{c}$, in this case only two fungi, $P$. digitatum $(\mathrm{PD})$ and $P$. italicum (PI) were partially inhibited. These results confirmed the importance of the available silver content in the material for a good fungicidal activity, but also indicated that the minimum dose of Agzeolite needed for achieving a biocidal effect depends on the fungal species. Similar results were obtained with LTA-zeolites and no important differences in fungicidal activity between LTA and FAU zeolites were observed (data not shown).

These results show that there were significant differences, when the fungicidal and bactericidal effects of Ag-loaded materials were compared. The zeolites with low silver content (Figure ${ }^{\wedge} 4<x$ figr $4>$ ) presented a very important antibacterial activity, whilst those with a similar concentration of silver were, in general, much less effective against fungi

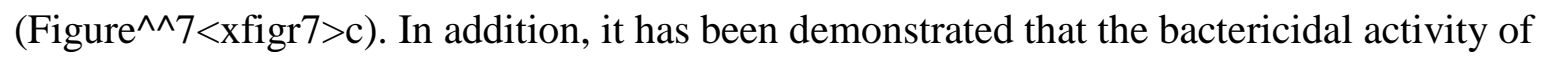
the material depends on the type of zeolite but this is not so important for the antifungal activity. The more complex cellular organization of fungal eukaryotic cells and their cellular wall structure may explain the higher Ag-zeolite concentration needed for killing fungi than bacteria. Hence, even though each particular species of bacteria and fungi can show a different degree of susceptibility to the antimicrobial action of Ag-zeolites, the different nature of fungi and bacteria influences the silver biocide action against these microorganisms. 


\section{Conclusion}

Silver exchanged zeolites showed notable antifungal and antibacterial activities, highlighting their potential as biocidal materials. It was observed that Ag-FAU presented better antibacterial activity than Ag-LTA zeolites, probably because FAU composition and topology favors the release of active silver species and these species interact more easily with the bacterial cells. Both zeolites showed a better biocidal activity against Gram-negative than against Gram-positive bacteria, probably due to the different wall cell properties of these microorganisms. The characterization of treated bacteria after the $i n^{\wedge}$ vitro experiments in presence of Ag-exchanged zeolite proved the multi target action of silver against bacterial cells. It was also observed that the Ag-zeolites were more active against bacteria than fungi, being the antifungal activity highly dependent on the fungus species. In this case, it seems that the structure of the zeolite was not so determinant for the antifungal activity of the material as it was for its antibacterial activity.

\section{Supporting information Summary}

The preparation process of the materials, the characterization techniques used to determine their physico-chemical properties and the biocide test employed in the work are described in detail in the supporting information (SI).

\section{Acknowledgements}

The authors thank the <cgs $>$ Spanish Ministry of Economy and Competitiveness $</$ cgs $>$ through $<$ cgn $>$ MAT-2015-71842$\mathrm{P}</$ cgn $>$ and $<$ cgn $>$ SEV-2016-0683</cgn $>$ for the financial support and J.L. Cerrillo wish to thank Spanish Ministry of Economy and Competitiveness for the Severo Ochoa PhD fellowship (SVP-2014-068600).

$<$ lit1><jnl>D. Dai, A. ${ }^{\wedge} \mathrm{J}$. Prussin, L. ${ }^{\wedge \wedge}$ C. Marr, P.^^J. Vikesland, M. ${ }^{\wedge \wedge}$ A. Edwards, A. Pruden, Environ. Sci. Technol. 2017, 51, 7759--7774</jnl>.

$<$ lit2 $><$ jnl $>$ R.^^M. Klevens, R. Edwards Jonathan, L. Richards Chesley, Jr., C. Horan Teresa, P. Gaynes Robert, A. Pollock Daniel, M. Cardo Denise, Public Health Rep 2007, 122, $160--166</$ jnl $>$.

$<$ lit3><jnl>M.^^A. Busolo, P. Fernandez, M.^^J. Ocio, J.^^M. Lagaron, Food Addit. Contam., Part A 2010, 27, 1617--1626</jnl>. 
$<$ lit4><jnl>D.^^R. Monteiro, L. ${ }^{\wedge \wedge}$ F. Gorup, A. ${ }^{\wedge \wedge}$ S. Takamiya, A. ${ }^{\wedge}$ C. Ruvollo-Filho, E. Rodrigues de Camargo, D.^^B. Barbosa, Int. J. Antimicrob. Agents 2009, 34, 103-$110</ \mathrm{jnl}>$.

<lit5><other>htttp://www.silverinstitute.org, 3rd Nov 2017, The Silver Institute, Washington D.C $</$ other $>$.

$<$ lit6><jnl $>$ W. ${ }^{\wedge}$ K. Jung, H.^^C. Koo, K. ${ }^{\wedge}$ W. Kim, S. Shin, S.^^H. Kim, Y.^^H. Park, Appl. Environ. Microbiol. 2008, 74, 2171--2178</jnl>.

$<$ lit7 $><$ jnl $>$ M.^^J. Sanchez, J.^^E. Mauricio, A.^^R. Paredes, P. Gamero, D. Cortes, Mater. Lett. 2017, 191, 65--68</jnl>.

$<$ lit8 ><jnl>P. Lalueza, M. Monzon, M. Arruebo, J. Santamaria, Mater. Res. Bull. 2011, 46, 2070--2076</jnl >

$<$ lit9><jnl>T. Haile, G. Nakhla, J. Zhu, H. Zhang, J. Shugg, Microporous Mesoporous Mater. 2009, 127, 32--40</jnl >

$<$ lit10 $><$ jnl $>$ P. Saint-Cricq, Y. Kamimura, K. Itabashi, A. Sugawara-Narutaki, A. Shimojima, T. Okubo, Eur. J. Inorg. Chem. 2012, 2012, 3398--3402, S3398/3391S3398/3392</jnl $>$.

$<$ lit11><jnl>Y. Matsumura, K. Yoshikata, S.-i. Kunisaki, T. Tsuchido, Appl. Environ. Microbiol. 2003, 69, 4278--4281</jnl>.

<lit12><jnl> V.^^J. Inglezakis, J. Colloid Interface Sci. 2005, 281, 68--79</jnl>.

$<$ lit13><jnl>A. ${ }^{\wedge}$ M. Fonseca, I.^^C. Neves, Microporous Mesoporous Mater. 2013, 181, 83-$87</$ jnl $>$.

$<$ lit14 ><jnl>R. Amorim, N. Vilaca, O. Martinho, R. ${ }^{\wedge}$ M. Reis, M. Sardo, J. Rocha, A. ${ }^{\wedge}$ M.

Fonseca, F. Baltazar, I.^^C. Neves, J. Phys. Chem. C 2012, 116, 25642--25650</jnl>.

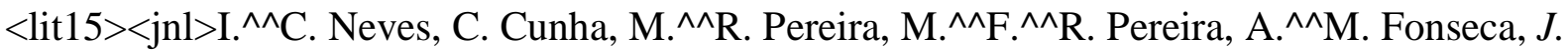
Phys. Chem. C 2010, 114, 10719--10724</jnl>. 
$<$ lit16><jnl>K. Gora-Marek, K.^^A. Tarach, Z. Piwowarska, M. Laniecki, L. Chmielarz, Catal. Sci. Technol. 2016, 6, 1651--1660</jnl>.

$<$ lit17><jnl>S.^^A. Regenhardt, C. ${ }^{\wedge}$ I. Meyer, A. ${ }^{\wedge}$ F. Trasarti, A. Monzon, T. ${ }^{\wedge}$ F. Garetto, Chem. Eng. J. (Amsterdam, Neth.) 2012, 198--199, 18--26</jnl>.

$<$ lit18><jnl>S. Demirci, Z. Ustaoglu, G.^^A. Yilmazer, F. Sahin, N. Bac, Appl. Biochem. Biotechnol. 2014, 172, 1652--1662</jnl>.

$<$ lit19><jnl>R. Tekin, N. Bac, Microporous Mesoporous Mater. 2016, 234, 55--60</jnl>. $<$ lit20><jnl $>$ L. Ferreira, A. ${ }^{\wedge}$ M. Fonseca, G. Botelho, C. Almeida-Aguiar, I. ${ }^{\wedge}$ C. Neves, Microporous Mesoporous Mater. 2012, 160, 126--132</jnl>.

$<$ lit21 ><jnl>P. Lalueza, M. Monzon, M. Arruebo, J. Santamaria, Chem. Commun.

(Cambridge, $U .^{\wedge \wedge} K$. .) 2011, 47, 680--682</jnl> .

$<$ lit22 ><jnl>K. Kawahara, K. Tsuruda, M. Morishita, M. Uchida, Dent. Mater. 2000, 16, 452$-455</$ jnl $>$.

$<$ lit23><jnl >R. ${ }^{\wedge}$ S. Bedi, R. Cai, C. O'Neill, D.^^E. Beving, S. Foster, S. Guthrie, W. Chen, Y. Yan, Microporous Mesoporous Mater. 2012, 151, 352--357</jnl>.

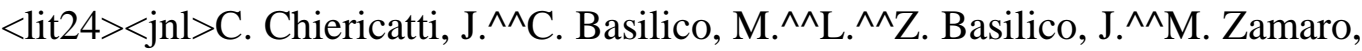
Microporous Mesoporous Mater. 2014, 188, 118--125</jnl>.

$<$ lit25 $><$ jnl $>$ J. ${ }^{\wedge}$ L. Cerrillo, A.^^E. Palomares, F. Rey, S. Valencia, L. Palou, M.^^B. PerezGago, Microporous Mesoporous Mater. 2017, 254, 69--76</jnl>.

$<$ lit26><jnl>A. Mayoral, T. Carey, P.^^A. Anderson, I. Diaz, Microporous Mesoporous

Mater. 2013, 166, 117--122</jnl >.

$<$ lit27><jnl>B. Kaur, R. Srivastava, B. Satpati, K.^^K. Kondepudi, M. Bishnoi, Colloids Surf., $B$ 2015, 135, 201--208</jnl >.

$<$ lit28><jnl>B. Kwakye-Awuah, C. Williams, M.^^A. Kenward, I. Radecka, J. Appl.

Microbiol. 2008, 104, 1516--1524</jnl>.

$<$ lit29><jnl>T. Sun, K. Seff, Chem. Rev. (Washington, D.^^C.) 1994, 94, 857--870</jnl>. 
$<$ lit30><jnl >E. Sayah, D. Brouri, P. Massiani, Catal. Today 2013, 218--219, 10--17</jnl>.

$<$ lit31><jnl>A. Satsuma, J. Shibata, K.-I. Shimizu, T. Hattori, Catal. Surv. Asia 2005, 9, 75-$85</$ jnl $>$.

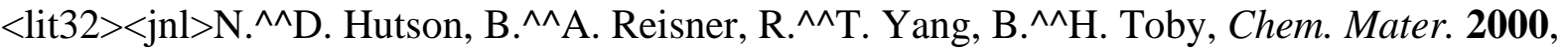
12, 3020--3031</jnl >

$<$ lit33><jnl>Q.^^L. Feng, J. Wu, G. ${ }^{\wedge} \mathrm{Q}$. Chen, T. ${ }^{\wedge}$ N. Kim, J.^^${ }^{\wedge}$. Kim, J. Biomed. Mater. Res. 2000, 52, 662--668</jnl >.

$<$ lit34><other>G.^^E. Brown, J.^^H. Eckert, Compendium of Citrus Diseases, 2nd ed., American Phytopathological Society Press, $2000</ o t h e r>$.

Figure $^{\wedge \wedge} 1 \quad$ XRD patterns of parent $($ LTA-1<?_>Na and FAU-2.4<?_>Na) and high silver content zeolites (LTA-1<?_>Ag(high) and FAU-2.4<?_>Ag(high)).

Figure $^{\wedge} 2$ SEM micrographs of LTA zeolites (up): parent zeolite (right), LTA with high silver content (left) and LTA with low silver content (middle). Ag mapping (down) of the AgLTAs where silver are the blue points (magnification of x10000).

Figure $^{\wedge} 3$ Bactericide activity (MIC) against S.aureus and E.coli in Tryptic Soy Broth medium after 2 days at $37^{\wedge}{ }^{\circ} \mathrm{C}$ of different LTA-1 zeolites (sodic form, high Ag content and low Ag content).

Figure $^{\wedge} 4 \quad$ Bactericide activity (MIC) against S.aureus and E.coli in Tryptic Soy Broth medium after 2 days at $37^{\wedge} \mathrm{C}$ of different $\mathrm{Ag}$-exchanged zeolites with low Ag content.

Figure $^{\wedge \wedge}$ HRTEM images of a suspension of healthy S.aureus bacteria without biocide agent (left) and a suspension of death S.aureus bacteria and crystals of zeolite FAU2.4<?_> Ag(low) as biocide agent (right).

Figure $^{\wedge \wedge} 6 \quad$ Mapping of a HRTEM image of a suspension containing S.aureus bacteria and crystals of FAU-2.4<?_> Ag(low) zeolite. Ag in yellow, Si in blue and Os in purple. 
Figure^^7 Inhibition percentage of the growth of different fungi after different periods of incubation of diverse Ag-faujasite at different concentrations. For each type of Ag-zeolite, columns with diverse letters are significantly different according to Fisher's protected least significant differences test applied after an analysis of variance $(\mathrm{P}<0.05)$.

Table^^1 Chemical composition of parent and Ag-loaded zeolites

\%wt. Ag \%wt. Na Si/Al molar ratio \%Ag exchange

\begin{tabular}{lllll}
\hline LTA-1<?_>Na & - & 15.3 & 1.0 & - \\
LTA-1<?_>Ag(high) & 48.4 & 0.5 & 0.9 & 95.9 \\
LTA-1^^Ag(low) & 1.8 & 10.3 & 0.9 & 2.7 \\
FAU-2.4<?_>Na & - & 9.7 & 2.4 & - \\
FAU-2.4<?_>Ag(high) & 30.6 & 1.2 & 2.5 & 93.4 \\
FAU-2.4<?_>Ag(low) & 1.3 & 6.8 & 2.4 & 3.4 \\
\hline
\end{tabular}

